\title{
A newly identified protein of Leptospira interrogans mediates binding to laminin
}

\author{
Mariana T. Longhi, ${ }^{1}$ Tatiane R. Oliveira, ${ }^{1}$ Eliete C. Romero, ${ }^{2}$ \\ Amane P. Gonçales, ${ }^{3}$ Zenaide M. de Morais, ${ }^{3}$ Silvio A. Vasconcellos ${ }^{3}$ \\ and Ana L. T. O. Nascimento ${ }^{1,4}$ \\ ${ }^{1}$ Centro de Biotecnologia, Instituto Butantan, Avenida Vital Brazil 1500, 05503-900 São Paulo, \\ SP, Brazil \\ ${ }^{2}$ Divisão de Biologia Medica, Instituto Adolfo Lutz, Sao Paulo, SP, Brazil \\ ${ }^{3}$ Laboratório de Zoonoses Bacterianas do VPS, Faculdade de Medicina Veterinária e Zootecnia, \\ USP, Avenida Prof. Dr Orlando Marques de Paiva 87, 05508-270 São Paulo, SP, Brazil \\ ${ }^{4}$ Interunidades em Biotecnologia, Instituto de Ciências Biomédicas, USP, Avenida Prof. Lineu \\ Prestes 1730, 05508-900 São Paulo, SP, Brazil
}

Correspondence

Ana L. T. O. Nascimento

tabet@butantan.gov.br

Received 14 April 2009

Accepted 10 June 2009
Pathogenic Leptospira is the aetiological agent of leptospirosis, a life-threatening disease that affects populations worldwide. The search for novel antigens that could be relevant in hostpathogen interactions is being pursued. These antigens have the potential to elicit several activities, including adhesion. This study focused on a hypothetical predicted lipoprotein of Leptospira, encoded by the gene LIC12895, thought to mediate attachment to extracellular matrix (ECM) components. The gene was cloned and expressed in Escherichia coli BL21 Star (DE3)pLys by using the expression vector pAE. The recombinant protein tagged with $\mathrm{N}$-terminal hexahistidine was purified by metal-charged chromatography and characterized by circular dichroism spectroscopy. The capacity of the protein to mediate attachment to ECM components was evaluated by binding assays. The leptospiral protein encoded by LIC12895, named Lsa27 (leptospiral surface adhesin, $27 \mathrm{kDa}$ ), bound strongly to laminin in a dose-dependent and saturable fashion. Moreover, Lsa27 was recognized by antibodies from serum samples of confirmed leptospirosis specimens in both the initial and the convalescent phases of the disease. Lsa27 is most likely a surface protein of Leptospira as revealed in liquid-phase immunofluorescence assays with living organisms. Taken together, these data indicate that this newly identified membrane protein is expressed during natural infection and may play a role in mediating adhesion of $L$. interrogans to its host.

\section{INTRODUCTION}

Leptospirosis is a re-emerging infectious disease caused by pathogenic spirochaetes of the genus Leptospira. The disease is more prevalent in tropical and subtropical regions, and in developing countries it produces large urban epidemics with significant mortality, mainly during the rainy season (Bharti et al., 2003). In the host, leptospirosis has a biphasic clinical presentation beginning with septicaemia followed by an immune phase with antibody production and urinary excretion of leptospires. Children primarily show fever, vomiting, headache,

Abbreviations: CD, circular dichroism; ECM, extracellular matrix; L-IFA, liquid-phase immunofluorescence assay; MAT, microscopic agglutination test.

The GenBank/EMBL/DDBJ accession number for LIC12895 is YP_002811. diarrhoea and abdominal and generalized muscle pain, whereas adults have fever, headache, anorexia, muscle pain and constipation (Faine et al., 1999). The most severe form of leptospirosis, known as Weil's syndrome, seen in 5-15\% of patients, is a multisystemic febrile illness, chiefly with hepatic, renal and pulmonary involvement and with a mortality rate of 5-40\% (Faine et al., 1999; Bharti et al., 2003). Leptospirosis also has a great economic impact on the agricultural industry, as the disease affects livestock, inducing abortions, stillbirths, infertility, reduced milk production and death (Faine et al., 1999; Plank \& Dean, 2000).

Functional genomics studies, including transcription profiles, gene cloning and protein expression and characterization, complement in silico analysis and help our understanding of bacterial pathogenesis (Palaniappan et al., 2007). The genomes of pathogenic Leptospira have been 
sequenced (Ren et al., 2003; Nascimento et al., 2004a, b; Bulach et al., 2006) and in silico analysis has identified more than 200 predicted outer-membrane proteins (Nascimento et al., 2004a, b). These proteins are potential targets for inducing immune responses during host infection and therefore constitute targets for immune protection through mechanisms such as antibody-dependent phagocytosis and killing mediated by complement. In addition, it is possible that a number of these membrane proteins mediate the initial adhesion to host cells (Merien et al., 2000; Barbosa et al., 2006; Choy et al., 2007; Stevenson et al., 2007; Atzingen et al., 2008; Hoke et al., 2008; Hauk et al., 2008; Carvalho et al., 2009).

Since the whole genome of Leptospira interrogans serovar Copenhageni was fully sequenced (Nascimento et al., 2004a), several predicted surface-coding sequences have been under study in our laboratory (Gamberini et al., 2005; Barbosa et al., 2006; Vieira et al., 2007; Atzingen et al., 2008; Gómez et al., 2008; Oliveira et al., 2008). In the present study, we focused on a novel hypothetical predicted lipoprotein of unknown function, encoded by the gene LIC12895. The gene was cloned and the protein was expressed using Escherichia coli as a heterologous host system. The recombinant protein of $26.5 \mathrm{kDa}$ was purified and its capacity to mediate attachment to various extracellular matrix (ECM) components was evaluated. We found that this novel leptospiral protein bound strongly to laminin. The protein, termed Lsa27 (leptospiral surface adhesin of $27 \mathrm{kDa}$ ), was expressed on the surface of bacteria as it was detected by an immunofluorescence assay using intact living leptospires. In addition, Lsa27 is present during infection as the protein was recognized by antibodies in serum samples from individuals with confirmed leptospirosis, thus suggesting a possible function of this protein in pathogenesis.

\section{METHODS}

Bacterial strains and sera. The non-pathogenic Leptospira biflexa (serovar Patoc strain Patoc 1) and the pathogenic L. interrogans (serovars Canicola strain Hond Utrecht IV, Copenhageni strain M-20, Hardjo strain Hardjoprajtino, Icterohaemorrhagiae strain RGA and Pomona strain Pomona), Leptospira borgpetersenii (serovar Castelonis strain Castellon 3), Leptospira kirschneri (serovar Grippotyphosa strain Moskva V) and Leptospira santarosai (serovar Shermani strain $1342 \mathrm{~K}$ ) were cultured at $28{ }^{\circ} \mathrm{C}$ under aerobic conditions in liquid Ellinghausen-McCullough-Johnson-Harris medium (Difco) with $10 \%$ rabbit serum, enriched with L-asparagine $(0.015 \%)$, sodium pyruvate $(0.001 \%)$, calcium chloride $(0.001 \%)$, magnesium chloride $(0.001 \%)$, peptone $(0.03 \%)$ and meat extract $(0.02 \%)$ (all w/v) (Turner, 1970). Leptospira cultures were maintained at the Faculdade de Medicina Veterinária e Zootecnia, USP, São Paulo, SP, Brazil. Confirmed leptospirosis serum samples were from the Instituto Adolfo Lutz collection, São Paulo, SP, Brazil.

Characterization of the protein in silico. Predicted coding sequence LIC12895 was selected from the L. interrogans serovar Copenhageni genome sequences (Nascimento et al., 2004a, b) based on its cellular localization prediction by the PSORT (http://psort.nibb. ac.jp; Nakai \& Horton, 1999; Nakai \& Kanehisa, 1991) and P-
Classifier (http://protein.bii.a-star.edu.sg/localization/gram-negative/ index.html; Wang et al., 2005) programs. The SMART (http:// smart.embl-heidelberg.de/; Schultz et al., 1998; Letunic et al., 2006), Pfam (http://www.sanger.ac.uk/Software/Pfam/; Finn et al., 2006) and LipoP (http://www.cbs.dtu.dk/services/LipoP/; Juncker et al., 2003) web servers were used to search for predicted functional and structural domains within the amino acid sequences of the selected sequences. The predicted sequence of the lipobox was evaluated by using the SpLip program, as described by Setubal et al. (2006).

Construction of a plasmid for expression in E. coli. The nucleotide sequence of gene LIC12895 was obtained by PCR amplification from genomic DNA of $L$. interrogans serovar Copenhageni using the primer pair 5'-GGATCCCTGAAATATACGAA-3' (forward) and 5'-GAATTCTTACTGTTCTCCTTC-3' (reverse) containing restriction sites for EcoRI and BamHI (underlined), respectively. The PCR-amplified products were cloned into pGEM-T vector (Promega) and positive clones were selected by DNA restriction analysis and further confirmed by nucleotide sequencing analysis. After confirmation of the sequence, the insert of 675 bp was removed by digestion with the enzymes indicated and ligated into pAE vector (Ramos et al., 2004), previously digested with the same enzymes. The resulting plasmid, pAE-LIC12895, was transformed into E. coli BL21 Star (DE3)pLys expression host cells.

Expression and purification of Lsa27. Protein expression was obtained by inoculating $8 \mathrm{ml}$ of a culture grown overnight in $200 \mathrm{ml}$ Luria-Bertani medium containing $100 \mu \mathrm{g}$ ampicillin $\mathrm{ml}^{-1}$ and $50 \mu \mathrm{g}$ chloramphenicol $\mathrm{ml}^{-1}$. The culture was grown with continuous shaking at $37{ }^{\circ} \mathrm{C}$ to an $\mathrm{OD}_{600}$ of $0.6-0.8$ and then induced for $3 \mathrm{~h}$ under constant agitation at $37^{\circ} \mathrm{C}$ in the presence of $0.1 \mathrm{mM}$ IPTG. The cells were harvested by centrifugation and the bacterial cell pellet was resuspended in sonication buffer $[20 \mathrm{mM}$ Tris/ $\mathrm{HCl}(\mathrm{pH} 8.0)$, $200 \mathrm{mM} \mathrm{NaCl}, 200 \mu \mathrm{g}$ lysozyme $\mathrm{ml}^{-1}, 2 \mathrm{mM}$ PMSF and $1 \%$ Triton $\mathrm{X}-100$ ] and lysed on ice with the aid of a sonicator (Ultrasonic Processor; GE Healthcare). The bacterial cell lysate was centrifuged at $3000 \mathrm{~g}$ for $15 \mathrm{~min}$ at $4{ }^{\circ} \mathrm{C}$. The supernatant was loaded onto $\mathrm{Ni}^{2+}$ charged beads of a chelating fast-flow chromatographic column. The column was washed extensively with buffer containing $20 \mathrm{mM}$ Tris/ $\mathrm{HCl}(\mathrm{pH} 8.0), 200 \mathrm{mM} \mathrm{NaCl}$ and $5 \mathrm{mM}$ imidazole. Bound protein was eluted with washing buffer containing $500 \mathrm{mM}$ imidazole. The efficiency of purification of Lsa27 was evaluated by $15 \%$ SDS-PAGE. Fractions containing the eluted protein were pooled and purified again after diluting 1:100 in washing buffer without imidazole, to remove contaminating E. coli proteins. Fractions containing the recombinant protein were dialysed extensively against PBS containing $1 \mathrm{mM}$ PMSF.

Circular dichroism (CD) spectroscopy. CD spectroscopy measurements were performed at $20{ }^{\circ} \mathrm{C}$ in a Jasco J-810 spectropolarimeter (Japan Spectroscopic) equipped with a Peltier unit for temperature control. Purified recombinant protein was dialysed into $10 \mathrm{mM}$ sodium phosphate buffer at a concentration of $20 \mu \mathrm{M}$. Far-UV (185$260 \mathrm{~nm}$ ) spectra were acquired using a $1 \mathrm{~mm}$ path-length cell at $0.5 \mathrm{~nm}$ intervals and five scans were accumulated and the mean value determined. The molar ellipticity $(\Phi)$ is expressed in degrees $\mathrm{cm}^{-2}$ $\mathrm{dmol}^{-1}$.

DNA and RNA extraction. The DNA from different serovars of Leptospira species was extracted from pellets with a guanidine detergent lysing solution (DNAzol; Invitrogen), essentially as described by Oliveira et al. (2008). PCR amplifications were performed using $2 \mu \mathrm{l} \mathrm{cDNA}$ to amplify the cDNA-specific gene. Sample quantity and integrity were verified by amplification of a 1042 bp $16 \mathrm{~S}$ rRNA gene fragment using the primers 16S-F ( $5^{\prime}$ CAAGTCAAGCGGAGTAGCAATACTCAGC-3') and 16S-R (5'GATGGCAACATAAGGTGAGGGTTGC-3'). 
Microscopic agglutination test (MAT). A microscopic agglutination test was performed according to Faine et al. (1999) using a battery of 22 serovars of Leptospira species as antigens, as described previously (Oliveira et al., 2008).

ELISA for detection of human antibodies. Detection of human IgG and IgM antibodies against Lsa27 was performed as described previously (Oliveira et al., 2008; Rodrigues et al., 2003). Each serum sample was added in duplicate wells at a 1:100 dilution. Cut-off points were set at 3 standard deviations above the mean $A_{492}$ of sera from six individuals who had never been exposed to leptospirosis, from the city of São Paulo.

Production of polyclonal antiserum against Lsa27. Four female $\mathrm{BALB} / \mathrm{c}$ mice (4-6 weeks old) were immunized subcutaneously with $10 \mu \mathrm{g} \mathrm{Lsa27.} \mathrm{The} \mathrm{recombinant} \mathrm{protein} \mathrm{was} \mathrm{adsorbed} \mathrm{in} 10 \%(\mathrm{v} / \mathrm{v})$ Alhydrogel $\left[2 \% \mathrm{Al}(\mathrm{OH})_{3}\right.$; Brenntag Biosector], used as an adjuvant. Two subsequent booster injections were given at 2-week intervals with the same protein preparation. Negative-control mice were injected with PBS. Two weeks after each immunization, mice were bled from the retro-orbital plexus and pooled sera were analysed by ELISA for determination of antibody titres. All animal studies were approved by the Ethics Committee of the Instituto Butantan, São Paulo, SP, Brazil.

Protein conservation among leptospiral strains. Bacterial cultures of Leptospira species were harvested by centrifugation, washed three times with PBS containing $5 \mathrm{mM} \mathrm{MgCl}_{2}$ and resuspended in PBS. A sample from each strain was separated by $15 \%$ SDS-PAGE and the proteins were transferred to nitrocellulose membrane using semi-dry equipment (GE Healthcare). The membrane was blocked overnight at $4{ }^{\circ} \mathrm{C}$ with $5 \%$ non-fat dried milk and $2.5 \%$ BSA in PBS. After three washings with PBS/Tween 20, the membrane was incubated for $2 \mathrm{~h}$ at room temperature with antiserum against Lsa27 (diluted $1: 200$ ) produced in mice, followed by washings and incubation with horseradish peroxidase-conjugated goat anti-mouse IgG (diluted 1:5000) for $1 \mathrm{~h}$ at room temperature. The membrane was then washed and the reactivity was revealed with diaminobenzidine and $\mathrm{H}_{2} \mathrm{O}_{2}$.

Binding of Lsa27 to ECM proteins. ELISA was performed as described previously (Barbosa et al., 2006) to test the adherence of Lsa27 to matrix component proteins. A 96-well plate was coated with $1 \mu \mathrm{g}$ per well of laminin, collagen type I, collagen type IV, cellular fibronectin or plasma fibronectin (Sigma-Aldrich) in $100 \mu \mathrm{l}$ PBS. MPL21, another recombinant protein, was used as a negative binding control. Ovalbumin, BSA and fetuin were bound to wells at the same concentration to serve as negative controls. For statistical analyses, the binding of Lsa27 to ECM macromolecules was compared with its binding to ovalbumin, BSA and fetuin by Student's two-tailed $t$-test.

Liquid-phase immunofluorescence assay (L-IFA). Localization of the LIC12895-encoded protein on the bacteria was performed by LIFA, as described previously (Oliveira et al., 2008). The immunofluorescently labelled leptospires were examined using a confocal LSM 510 META microscope (Zeiss).

\section{RESULTS}

\section{Bioinformatic analysis of the LIC12895 sequence}

The gene LIC12895 was identified on chromosome I by analysis of the probable open reading frames present in the genome of $L$. interrogans serovar Copenhageni (Nascimento et al., 2004a, b). LIC12895 was predicted to be a membrane protein, based on a search for sequence motifs by the programs PSORT (Nakai \& Kanehisa, 1991) and P-Classifier (Wang et al., 2005). The SMART server predicted a signal peptide from aa 1 to 20 . There was no putative conserved domain within this sequence, according to Pfam. The LipoP server predicted the LIC12895 coding sequence to be a lipoprotein with a cleavage site for signal peptidase II at aa 20-21 (Juncker et al., 2003), corroborating the result obtained using SpLip (Setubal et al., 2006). BLAST analysis showed that LIC12895 was identified in $L$. interrogans serovar Lai (79\% identity with LA0710) (Ren et al., 2003) but was absent in both the pathogenic $L$. borgpetersenii (Bulach et al., 2006) and the saprophytic $L$. biflexa (Picardeau et al., 2008) genome sequences.

\section{Cloning of the LIC12895 gene and expression of recombinant protein}

The 675 bp fragment amplified by PCR from genomic DNA of $L$. interrogans serovar Copenhageni was cloned and sequenced. The recombinant LIC12895-encoded protein of $26.5 \mathrm{kDa}$ was expressed as a full-length protein in $E$. coli BL21 Star (DE3)pLys and purified by $\mathrm{Ni}^{2+}$-charged chromatography. Fig. 1(a) shows the SDS-PAGE analysis of purified Lsa27 performed under denaturing conditions in the presence of the reducing agent 2-mercaptoethanol. The structural integrity of the purified protein was assessed by CD spectroscopy. As depicted in Fig. 1(b), Lsa27 presented a predominant signal of $\alpha$-helices with minimum ellipticities at 208 and $222 \mathrm{~nm}$ and a maximum at $192 \mathrm{~nm}$. The experimental data confirmed the secondary structure content previously predicted by computational analysis (http://bioinf.cs.ucl.ac.uk/psipred/).

\section{Analysis of the LIC12895 gene, its transcript and the protein among leptospiral reference strains}

To evaluate the conservation of the protein corresponding to the gene LIC12895 and its transcript, PCR and RT-PCR analysis were performed on a panel of leptospires comprising four pathogenic species, L. interrogans (serovars Canicola, Copenhageni, Icterohaemorrhagiae, Pomona and Hardjo), L. borgpetersenii serovar Castelonis, L. santarosai serovar Shermani and L. kirschneri serovar Grippotyphosa, and the non-pathogenic strain L. biflexa serovar Patoc. The results depicted in Fig. 2(a) show the presence of a specific amplification band corresponding to a 420 bp fragment of the LIC12895 gene from genomic DNA in $L$. interrogans serovars Copenhageni and Icterohaemorrhagiae. The bands observed in L. interrogans serovar Canicola and L. biflexa were smaller and were probably due to non-specific annealing of the primers. The bands observed with the species $L$. borgpetersenii, $L$. kirschneri and $L$. santarosai were of a similar size to that amplified from L. interrogans serovars Copenhageni and Icterohaemorrhagiae but were much less intense, probably due to the presence of sequences in their genome that have low similarity to the LIC12895 gene. The cDNA was detected only in the pathogenic strains of L. interrogans 


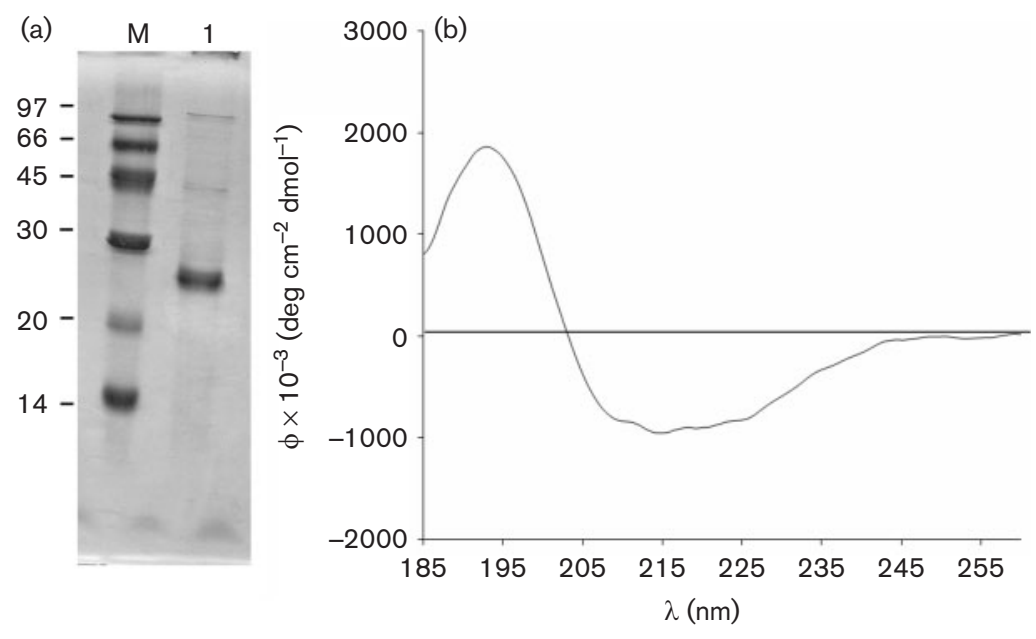

Fig. 1. (a) SDS-PAGE analysis of the purified recombinant protein corresponding to Lsa27 of $L$. interrogans serovar Copenhageni. Bacterial recombinant protein was expressed and purified as described in Methods. Lane M, molecular mass markers (kDa); lane 1, Lsa27 (2 $\mu \mathrm{g}$ recombinant protein). (b) CD spectrum of the recombinant Lsa27 protein, showing a predominant signal of $\alpha$-helices with minimum ellipticities at 208 and $222 \mathrm{~nm}$ and a maximum at $192 \mathrm{~nm}$. Far-UV CD spectra are presented as the mean of five scans recorded from 190 to $260 \mathrm{~nm}$.

serovars Copenhageni and Icterohaemorrhagiae (Fig. 2b). Protein expression confirmed these results, as protein bands were clearly seen with the same strains (Fig. 2c). The protein band detected with L. biflexa was probably due to non-specific binding, as no transcript was observed with this strain.

\section{Adhesion to ECM components}

Laminin, collagen types I and IV, cellular fibronectin, plasma fibronectin and the control proteins BSA, ovalbumin and fetuin were immobilized on microdilution wells and recombinant protein attachment was assessed by using an ELISA-based assay. As shown in Fig. 3(a), LIC12895encoded protein exhibited efficient adhesion to laminin. No statistically significant adhesion was observed with this protein when wells were coated with collagen types I and IV, plasma and cellular fibronectin or with the highly glycosylated control protein fetuin. MPL21, a recombinant protein used as a negative control, showed no significant attachment to any of the ECM components tested. The interactions of Lsa27 and MPL21 with laminin were also assessed on a quantitative basis, as illustrated in Fig. 3(b). A dose-dependent and saturable binding was observed when increasing concentrations of the recombinant protein $(0$ $1000 \mathrm{nM}$ ) were allowed to adhere to a fixed laminin concentration $(1 \mu \mathrm{g})$. Saturation level was reached at a protein concentration of $500 \mathrm{nM}$ (Fig. 3b). In the case of MPL21, a constant binding intensity was detected, which did not change with increasing protein concentration (Fig. $3 b)$.

\section{Reactivity of Lsa27 with serum samples from individuals with leptospirosis}

Serum antibodies (IgM and IgG) from individuals with confirmed early-phase and convalescent-phase leptospirosis were used to test recognition of Lsa27. A total of $39.5 \%$ of subjects presented antibodies $(\operatorname{IgM}+\operatorname{IgG})$ against the recombinant protein. Lsa27 was recognized by IgM and
IgG antibodies in both the early and convalescent phases of the disease (results not shown).

\section{Detection of protein corresponding to the LIC12895 gene in bacteria by confocal microscopy}

We used an L-IFA to demonstrate the expression of native LIC12895-encoded protein in L. interrogans. The genomic DNA of living leptospires was labelled by propidium iodide staining (Fig. 4a, d, g, j), followed by incubation with antiLsa27 antibody and secondary anti-mouse IgG antibodies conjugated to FITC (Fig. 4b, e). In control experiments, a green fluorescence could be observed with antisera that recognized LipL32 antigen (Fig. $4 \mathrm{~h}$ ), an outer-membrane protein, but not with GroEL, a protoplasmic cylinder marker (Fig. 4k). We observed that Lsa27 was located at the anterior end of the leptospires as a unique dot configuration. The localization of the protein on the leptospires was achieved by superimposing both fields and the results obtained are shown in Fig. 4(c, f, i, l) for each of the proteins Lsa27, LipL32 and GroEL.

\section{DISCUSSION}

The genome annotation of $L$. interrogans serovar Copenhageni predicted 184 coding sequences, some of which were expected to be exported to the leptospiral surface as lipoproteins (Nascimento et al., 2004a). The majority of these proteins were hypothetical with no assigned function. Among these 184, we selected proteins that were predicted to be present at the membrane of leptospires. Due to their location, these proteins are in contact with the host and may be involved in leptospiral pathogenesis and protective immunity. Host tissue adhesion and colonization are critical events in disease establishment. Bearing this in mind, we were able to identify leptospiral adhesins with ECM-binding properties (Atzingen et al., 2008; Barbosa et al., 2006) and proteins that were capable of promoting upregulation of cellular 

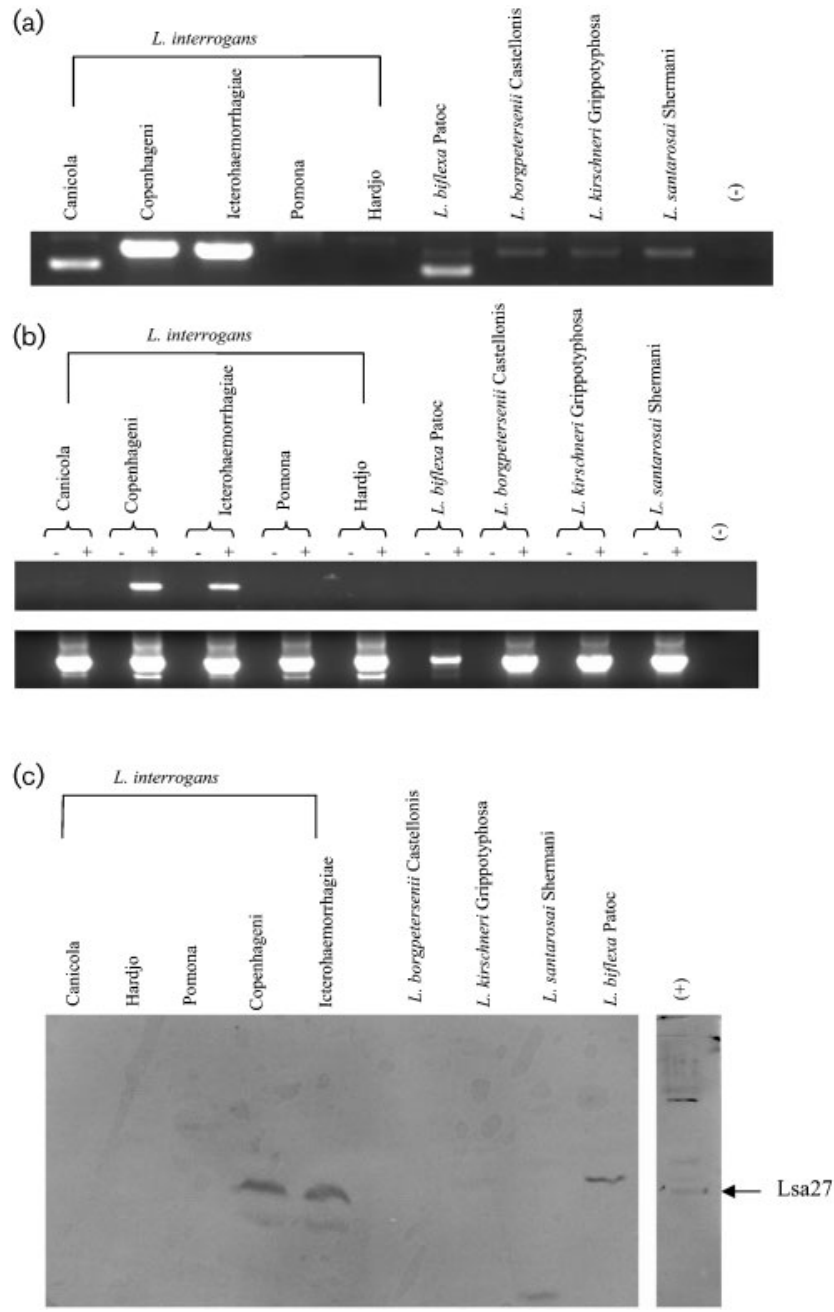

Fig. 2. Analysis of the LIC12895 gene, its transcript and the protein among different leptospiral strains. (a) Analysis by PCR of the LIC12895 gene in pathogenic serovars ( $L$. interrogans, $L$. borgpetersenii, L. santarosai and $L$. kirschneri) and in a nonpathogenic $L$. biflexa strain. The negative control contained no DNA, indicated by (-). (b) Semi-quantitative analysis by RT-PCR using $2 \mu \mathrm{g}$ total RNA extracted from different serovars belonging to the pathogenic species and the saprophytic $L$. biflexa serovar Patoc strain Patoc 1. 16S rRNA gene expression was used as an internal control. +, Reverse transcriptase present; -, reverse transcriptase omitted. (c) Western blot of whole-cell lysates of the same leptospiral strains probed with anti-Lsa27 antibody. The positive control (recombinant protein) is indicated by $(+)$.

adhesion molecules in endothelial cells (Gómez et al., 2008; Vieira et al., 2007).

We report in this work a novel $L$. interrogans protein encoded by the gene LIC12895, annotated in the genome as hypothetical and predicted to be a lipoprotein. The LIC12895-encoded protein was able to bind laminin in a dose-dependent and saturable manner. In addition, this protein was recognized by antibodies present in serum
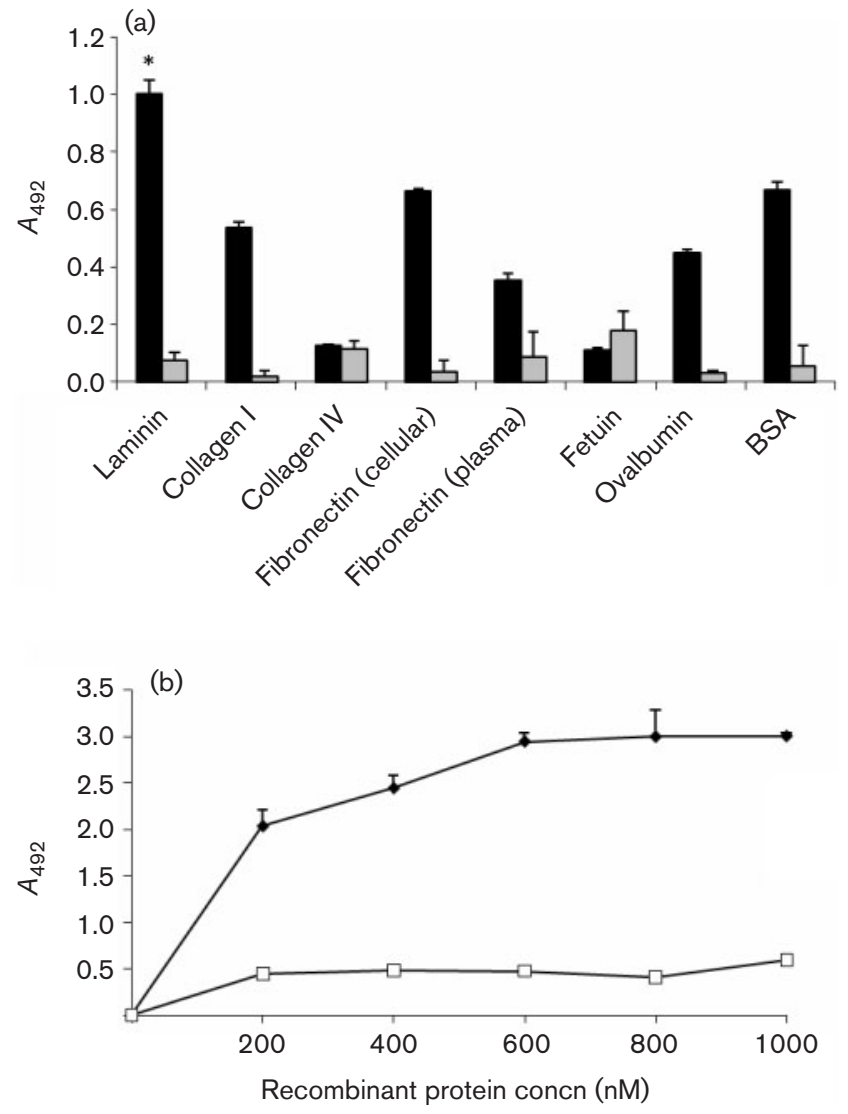

Fig. 3. Binding of Lsa27 to ECM components. (a) Laminin, collagen type I, collagen type IV, cellular fibronectin, plasma fibronectin and the control proteins fetuin, ovalbumin and BSA ( $1 \mu \mathrm{g}$ of each) were adsorbed to microtitre plates and incubated with $1 \mu \mathrm{g} \mathrm{Lsa27}$ (black columns) for $90 \mathrm{~min}$ at $37^{\circ} \mathrm{C}$. The protein MPL21 (grey columns) was included in the experiment, as negative recombinant protein control. After washing, Lsa27 attachment to the ECM components was detected with anti-Lsa27 and antiMPL21 polyclonal sera as described in Methods. Data represent means \pm SD from three independent experiments. Specific binding of Lsa27 to the ECM macromolecules was determined by comparison with the binding to fetuin, ovalbumin and BSA by Student's two-tailed $t$-test $\left({ }^{*}, P<0.05\right)$. (b) Lsa27 $(\Delta)$ and MPL21 $(\square)$ dose-dependent binding experiments. Wells were coated with $1 \mu \mathrm{g}$ laminin and incubated with increasing concentrations (0$1000 \mathrm{nM}$ ) of recombinant protein. ECM-bound Lsa27 and MPL21 were detected with anti-Lsa27 and anti-MPL21 antibodies, respectively. Data represent the mean $A_{492} \pm$ SEM in triplicate wells.

samples from patients diagnosed with leptospirosis. The presence of the LIC12895 gene was clearly demonstrated by PCR in $L$. interrogans serovars Copenhageni and Icterohaemorrhagiae. The faint bands detected in other species were probably due to some sequence similarity in these species. This is in agreement with BLAST analyses, which have shown the absence of the LIC12895 gene in the pathogenic L. borgpetersenii (Bulach et al., 2006) and the saprophytic L. biflexa (Picardeau et al., 2008) sequenced 

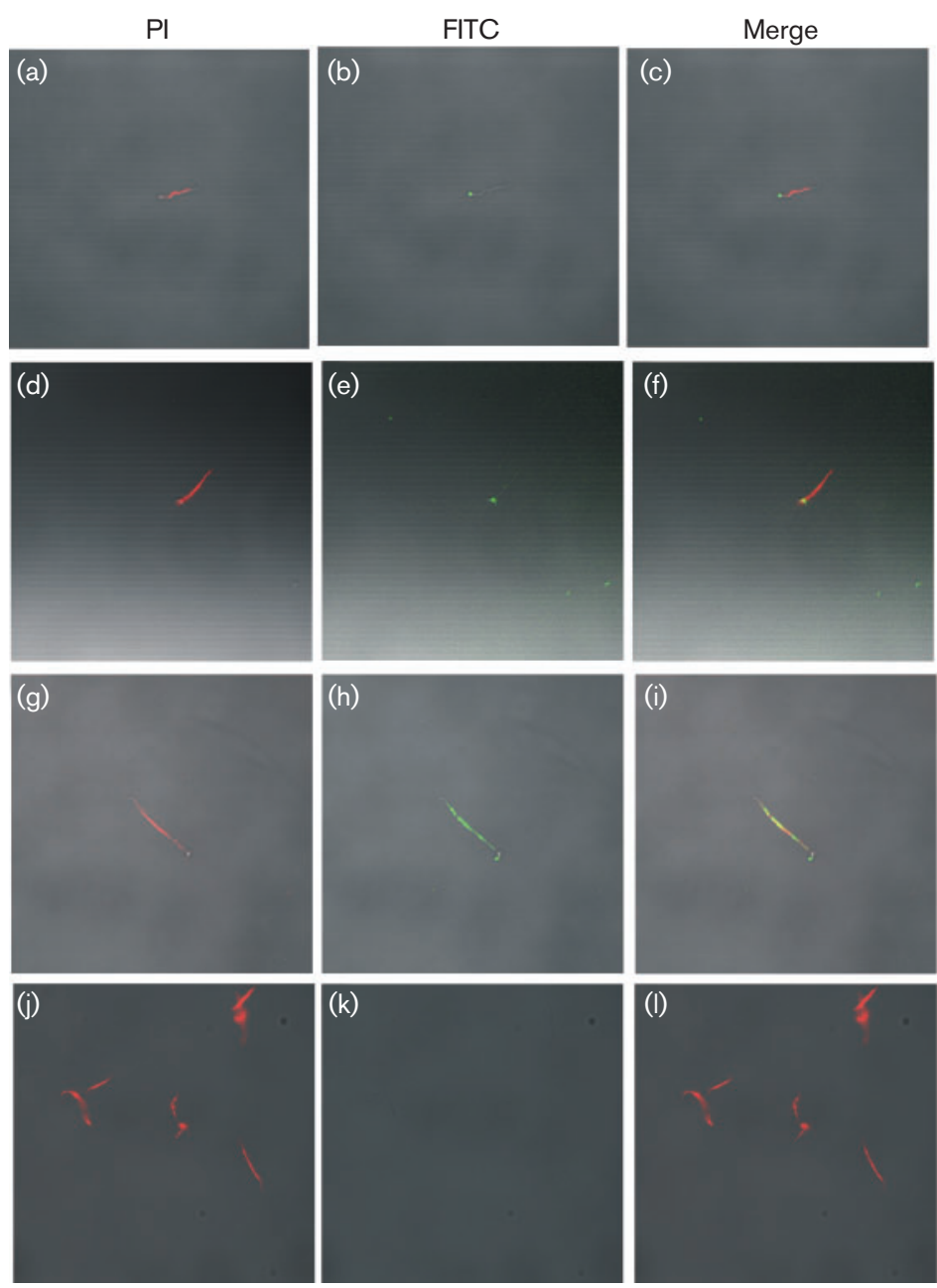
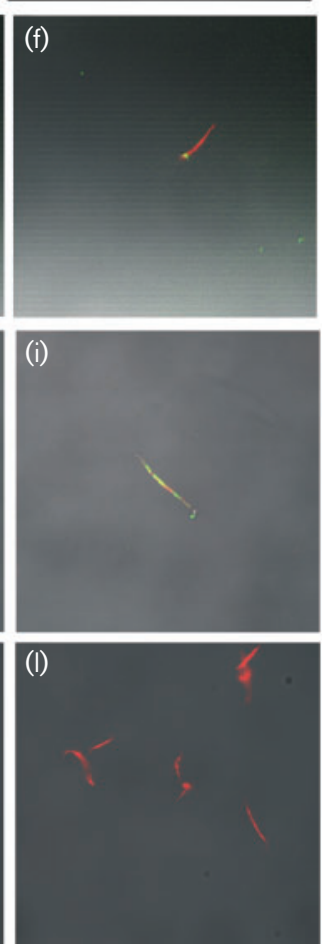

Lsa27

Lsa27

LipL32

GroEL
Fig. 4. Localization of Lsa27 in L. interrogans by L-IFA. Confocal microscopy was performed with live $L$. interrogans using antisera specific for Lsa27, LipL32 (surface-exposed lipoprotein) and GroEL (protoplasmic cylinder marker). FITC-conjugated secondary antibodies were used to detect the surface-bound antibodies ( $b, e, h$ and $k$ ). Leptospires were identified by propidium iodide staining of the DNA ( $a, d, g$ and j). Co-localization is shown in the merged images (c, $\mathrm{f}, \mathrm{i}$ and $\mathrm{l})$. Magnification, $\times 600$. genomes. Accordingly, the LIC12895 transcript as well as the protein were detected in $L$. interrogans serovars Copenhageni and Icterohaemorrhagiae strains. The protein in the bacterial extracts had a slightly higher molecular mass than the recombinant protein (see Fig. 2c). As LIC12895 is predicted to be a lipoprotein, it is possible that the proteins were in their lipidated form within the bacterium. Moreover, the coding sequence has been identified in the genome sequences of L. interrogans serovar Lai (Ren et al., 2003). This is interesting as all of these serovars belong to the same Icterohaemorrhagiae serogroup and, in humans, severe leptospirosis is frequently but not invariably caused by serovars of this serogroup (Faine et al., 1999; Levett, 2001). In addition, there is evidence that L. interrogans serovar Copenhageni is responsible for leptospirosis-associated severe pulmonary haemorrhagic syndrome in slum communities in Salvador, Brazil (Maciel et al., 2008). Thus, it is possible that the LIC12895-encoded protein may contribute to the pathogenesis of Leptospira from this serogroup.

The LIC12895-encoded protein was expressed in E. coli as a $26.5 \mathrm{kDa}$ full-length recombinant protein, named Lsa27.
Lsa27 was expressed in its soluble form by employing conditions such as low IPTG concentration and the E. coli BL21 Star (DE3)pLys expression host. Under these conditions, we succeeded in purifying the expressed Lsa27 as a major protein band. The maintenance of secondary structure of the recombinant protein after the purification process was one of our concerns, as some denatured proteins lose their immunogenicity and immunoprotection activities (Pertinhez et al., 2004). However, CD spectroscopy showed a predominant signal of $\alpha$-helical secondary structure content that validated Lsa27 for further studies.

Lsa27 showed ECM-binding properties and it is probable that it may have a function in attachment to host tissues. The protein exhibited a binding profile similar to that of the previously reported Lsa24, which is a laminin-binding adhesin (Barbosa et al., 2006), but distinct from that of other adhesins that have been reported to bind to different ECM macromolecules (Stevenson et al., 2007; Choy et al., 2007; Atzingen et al., 2008; Hoke et al., 2008; Hauk et al., 2008; Carvalho et al., 2009). We have previously shown the attachment of Leptospira to several ECM macromolecules, 
including laminin, collagen I, collagen IV, cellular fibronectin and plasma fibronectin (Barbosa et al., 2006).

The reactivity of the Lsa27 protein was detected against sera from both early MAT-negative and late MAT-positive phases of the illness. These results indicate that the Lsa27 protein is expressed and is immunogenic during natural infection and is likely to be exposed to the host cells. In fact, the results of bacterial cell localization of the Lsa27 protein with live leptospires using L-IFA (Oliveira et al., 2008) indicated that Lsa27 is surface-exposed. Polyclonal serum against the recombinant protein showed positive green fluorescence reactivity with Lsa27 that was similar to but much less intense than that obtained with the LipL32 outer-membrane protein, a major leptospiral antigen (Haake \& Matsunaga, 2002; Nally et al., 2007). The fluorescence obtained with Lsa27 in addition to the negative reactivity shown with the protoplasmic cylinder protein GroEL antiserum suggest that this protein is surface-exposed.

Revealing bacteria-host interactions at a molecular level will shed light on our understanding of host physiology and will facilitate the identification of novel vaccine targets against leptospirosis. Lsa27 is a newly identified, surfaceexposed adhesin of Leptospira that exhibits ECM-binding properties, is recognized by antibodies in both early and late phases of the disease and is present in serovars of $L$. interrogans that belong to a serogroup frequently associated with severe leptospirosis in humans (Faine et al., 1999; Levett, 2001; de Faria et al., 2008). Thus, it is possible that Lsa27 may have a role in the adhesion process and hence may contribute to leptospiral infection associated with the Icterohaemorrhagiae serogroup.

\section{ACKNOWLEDGEMENTS}

We are deeply indebted to Dr Toshie Kawano and Alexsander Seixas de Souza (Departamento de Parasitologia, Instituto Butantan, São Paulo, Brazil) for use of confocal facilities and helpful discussion. This research was supported by FAPESP, CNPq and Fundação Butantan, Brazil; M. T. L. and T. R. O. have fellowships from FAPESP (Brazil).

\section{REFERENCES}

Atzingen, M. V., Barbosa, A. S., De Brito, T., Vasconcellos, S. A., De Morais, Z. M., Lima, D. M., Abreu, P. A. \& Nascimento, A. L. (2008). Lsa21, a novel leptospiral protein binding adhesive matrix molecules and present during human infection. BMC Microbiol 8, 70.

Barbosa, A. S., Abreu, P. A., Neves, F. O., Atzingen, M. V., Watanabe, M. M., Vieira, M. L., Morais, Z. M., Vasconcellos, S. A. \& Nascimento, A. L. (2006). A newly identified leptospiral adhesin mediates attachment to laminin. Infect Immun 74, 6356-6364.

Bharti, A. R., Nally, J. E., Ricaldi, J. N., Matthias, M. A., Diaz, M. M., Lovett, M. A., Levett, P. N., Gilman, R. H., Willig, M. R. \& other authors (2003). Leptospirosis: a zoonotic disease of global importance. Lancet Infect Dis 3, 757-771.

Bulach, D. M., Zuerner, R. L., Wilson, P., Seemann, T., McGrath, A., Cullen, P. A., Davis, J., Johnson, M., Kuczek, E. \& other authors
(2006). Genome reduction in Leptospira borgpetersenii reflects limited transmission potential. Proc Natl Acad Sci U S A 103, 14560-14565.

Carvalho, E., Barbosa, A. S., Gómez, R. M., Cianciarullo, A. M., Hauk, P., Abreu, P. A., Fiorini, L. C., Oliveira, M. L., Romero, E. C. \& other authors (2009). Leptospiral TlyC is an extracellular matrix-binding protein and does not present hemolysin activity. FEBS Lett 583, 1381-1385.

Choy, H. A., Kelley, M. M., Chen, T. L., Moller, A. K., Matsunaga, J. \& Haake, D. A. (2007). Physiological osmotic induction of Leptospira interrogans adhesion: LigA and LigB bind extracellular matrix proteins and fibrinogen. Infect Immun 75, 2441-2450.

de Faria, M. T., Calderwood, M. S., Athanazio, D. A., McBride, A. J., Hartskeerl, R. A., Pereira, M. M., Ko, A. I. \& Reis, M. G. (2008). Carriage of Leptospira interrogans among domestic rats from an urban setting highly endemic for leptospirosis in Brazil. Acta Trop 108, 1-5.

Faine, S., Adler, B., Bolin, C. \& Perolat, P. (1999). Leptospira and Leptospirosis. Melbourne, Australia: MediSci.

Finn, R. D., Mistry, J., Schuster-Bockler, B., Griffiths-Jones, S., Hollich, V., Lassmann, T., Moxon, S., Marshall, M., Khanna, A. \& other authors (2006). Pfam: clans, web tools and services. Nucleic Acids Res 34, D247-D251.

Gamberini, M., Gómez, R. M., Atzingen, M. V., Martins, E. A., Vasconcellos, S. A., Romero, E. C., Leite, L. C., Ho, P. L. \& Nascimento, A. L. (2005). Whole-genome analysis of Leptospira interrogans to identify potential vaccine candidates against leptospirosis. FEMS Microbiol Lett 244, 305-313.

Gómez, R. M., Vieira, M. L., Schattner, M., Malaver, E., Watanabe, M. M., Barbosa, A. S., Abreu, P. A., De Morais, Z. M., Cifuente, J. O. \& other authors (2008). Putative outer membrane proteins of Leptospira interrogans stimulate human umbilical vein endothelial cells (HUVECS) and express during infection. Microb Pathog 45, 315322.

Haake, D. A. \& Matsunaga, J. (2002). Characterization of the leptospiral outer membrane and description of three novel leptospiral membrane proteins. Infect Immun 70, 4936-4945.

Hauk, P., Macedo, F., Romero, E. C., Vasconcellos, S. A., De Morais, Z. M., Barbosa, A. S. \& Ho, P. L. (2008). In LipL32, the major leptospiral lipoprotein, the $\mathrm{C}$ terminus is the primary immunogenic domain and mediates interaction with collagen IV and plasma fibronectin. Infect Immun 76, 2642-2650.

Hoke, D. E., Egan, S., Cullen, P. A. \& Adler, B. (2008). LipL32 is an extracellular matrix-interacting protein of Leptospira spp. and Pseudoalteromonas tunicata. Infect Immun 76, 2063-2069.

Juncker, A. S., Willenbrock, H., Von Heijne, G., Brunak, S., Nielsen, H. \& Krogh, A. (2003). Prediction of lipoprotein signal peptides in Gramnegative bacteria. Protein Sci 12, 1652-1662.

Letunic, I., Copley, R. R., Pils, B., Pinkert, S., Schultz, J. \& Bork, P. (2006). SMART 5: domains in the context of genomes and networks. Nucleic Acids Res 34, D257-D260.

Levett, P. N. (2001). Leptospirosis. Clin Microbiol Rev 14, 296-326.

Maciel, E. A., De Carvalho, A. L., Nascimento, S. F., De Matos, R. B., Gouveia, E. L., Reis, M. G. \& Ko, A. I. (2008). Household transmission of leptospira infection in urban slum communities. PLoS Negl Trop Dis 2, e154.

Merien, F., Truccolo, J., Baranton, G. \& Perolat, P. (2000). Identification of a $36-\mathrm{kDa}$ fibronectin-binding protein expressed by a virulent variant of Leptospira interrogans serovar icterohaemorrhagiae. FEMS Microbiol Lett 185, 17-22.

Nakai, K. \& Horton, P. (1999). PSORT: a program for detecting sorting signals in proteins and predicting their subcellular localization. Trends Biochem Sci 24, 34-36. 
Nakai, K. \& Kanehisa, M. (1991). Expert system for predicting protein localization sites in Gram-negative bacteria. Proteins 11, 95-110.

Nally, J. E., Whitelegge, J. P., Bassilian, S., Blanco, D. R. \& Lovett, M. A. (2007). Characterization of the outer membrane proteome of Leptospira interrogans expressed during acute lethal infection. Infect Immun 75, 766-773.

Nascimento, A. L., Ko, A. I., Martins, E. A., Monteiro-Vitorello, C. B., Ho, P. L., Haake, D. A., Verjovski-Almeida, S., Hartskeerl, R. A., Marques, M. V. \& other authors (2004a). Comparative genomics of two Leptospira interrogans serovars reveals novel insights into physiology and pathogenesis. J Bacteriol 186, 2164-2172.

Nascimento, A. L., Verjovski-Almeida, S., Van Sluys, M. A., MonteiroVitorello, C. B., Camargo, L. E., Digiampietri, L. A., Harstkeerl, R. A., Ho, P. L., Marques, M. V. \& other authors (2004b). Genome features of Leptospira interrogans serovar Copenhageni. Braz J Med Biol Res 37, 459-477.

Oliveira, T. R., Longhi, M. T., De Morais, Z. M., Romero, E. C., Blanco, R. M., Kirchgatter, K., Vasconcellos, S. A. \& Nascimento, A. L. (2008). Evaluation of leptospiral recombinant antigens MPL17 and MPL21 for serological diagnosis of leptospirosis by enzyme-linked immunosorbent assays. Clin Vaccine Immunol 15, 1715-1722.

Palaniappan, R. U., Ramanujam, S. \& Chang, Y. F. (2007). Leptospirosis: pathogenesis, immunity, and diagnosis. Curr Opin Infect Dis 20, 284-292.

Pertinhez, T. A., Sforca, M. L., Alves, A. C., Ramos, C. R., Ho, P. L., Tendler, M., Zanchin, N. I. \& Spisni, A. (2004). ${ }^{1} \mathrm{H},{ }^{15} \mathrm{~N}$ and ${ }^{13} \mathrm{C}$ resonance assignments of the apo Sm14-M20(C62V) protein, a mutant of Schistosoma mansoni Sm14. J Biomol NMR 29, 553-554.

Picardeau, M., Bulach, D. M., Bouchier, C., Zuerner, R. L., Zidane, N., Wilson, P. J., Creno, S., Kuczek, E. S., Bommezzadri, S. \& other authors (2008). Genome sequence of the saprophyte Leptospira biflexa provides insights into the evolution of Leptospira and the pathogenesis of leptospirosis. PLoS One 3, e1607.

Plank, R. \& Dean, D. (2000). Overview of the epidemiology, microbiology, and pathogenesis of Leptospira spp. in humans. Microbes Infect 2, 1265-1276.
Ramos, C. R., Abreu, P. A., Nascimento, A. L. \& Ho, P. L. (2004). A high-copy T7 Escherichia coli expression vector for the production of recombinant proteins with a minimal $\mathrm{N}$-terminal His-tagged fusion peptide. Braz J Med Biol Res 37, 1103-1109.

Ren, S. X., Fu, G., Jiang, X. G., Zeng, R., Miao, Y. G., Xu, H., Zhang, Y. X., Xiong, H., Lu, G. \& other authors (2003). Unique physiological and pathogenic features of Leptospira interrogans revealed by wholegenome sequencing. Nature 422, 888-893.

Rodrigues, M. H., Cunha, M. G., Machado, R. L., Ferreira, O. C., Jr, Rodrigues, M. M. \& Soares, I. S. (2003). Serological detection of Plasmodium vivax malaria using recombinant proteins corresponding to the $19-\mathrm{kDa}$ C-terminal region of the merozoite surface protein-1. Malar J 2, 39.

Schultz, J., Milpetz, F., Bork, P. \& Ponting, C. P. (1998). SMART, a simple modular architecture research tool: identification of signaling domains. Proc Natl Acad Sci U S A 95, 5857-5864.

Setubal, J. C., Reis, M., Matsunaga, J. \& Haake, D. A. (2006). Lipoprotein computational prediction in spirochaetal genomes. Microbiology 152, 113-121.

Stevenson, B., Choy, H. A., Pinne, M., Rotondi, M. L., Miller, M. C., Demoll, E., Kraiczy, P., Cooley, A. E., Creamer, T. P. \& other authors (2007). Leptospira interrogans endostatin-like outer membrane proteins bind host fibronectin, laminin and regulators of complement. PLoS One 2, e1188.

Turner, L. H. (1970). Leptospirosis. 3. Maintenance, isolation and demonstration of leptospires. Trans R Soc Trop Med Hyg 64, 623-646.

Vieira, M. L., D'Atri, L. P., Schattner, M., Habarta, A. M., Barbosa, A. S., de Morais, Z. M., Vasconcellos, S. A., Abreu, P. A., Gómez, R. M. \& Nascimento, A. L. (2007). A novel leptospiral protein increases ICAM-1 and E-selectin expression in human umbilical vein endothelial cells. FEMS Microbiol Lett 276, 172-180.

Wang, J., Sung, W. K., Krishnan, A. \& Li, K. B. (2005). Protein subcellular localization prediction for Gram-negative bacteria using amino acid subalphabets and a combination of multiple support vector machines. BMC Bioinformatics 6, 174. 